JANIS, Christine M., Department of Ecology and Evolutionary Biology, Brown University, Providence, RI 02912, U.S.A.

\title{
PATTERNS IN THE EVOLUTION OF HERBIVORY IN MAMMALS
}

Following the demise of the dinosaurs at the end of the Cretaceous, there was a long lag before mammalian herbivores evolved to take their place. Paleocene mammals generally termed "herbivorous" are not good analogs for modern herbivores: the "condylarth" groups were more generally omnivorous, and the other, larger archaic forms (pantodonts, uintatheres, etc.) had "shearing" types of teeth that were very small for their size, suggesting reliance on very soft (?aquatic) vegetation. True folivory was not apparent until the latest Paleocene, with the appearance of more shearing types of dentition in some phenacodontid "condylarths". Although the modern ungulate orders, Artiodactyla and Perissodactyla, first appeared in the early Eocene, and this time period heralded the first significant radiation of more terrestrially adapted ungulates, many of these taxa had dentitions more typical of omnivore/frugivores, and folivory was not common until the late Eocene.

Although "hypsodont" ungulates are known from the Paleogene, there is no evidence of true grazing ungulates (at least outside of South America) until around 10 MYA. This predates the isotopic evidence for $\mathrm{C} 4$ grasslands by some $3 \mathrm{MA}$, suggesting $\mathrm{C} 3$ grazing communities. Ungulate diversity was greatly reduced by late Cenozoic extinctions, which especially affected the large, specialized browsers. Our present-day conception of the range of ungulate herbivore diversity is highly biased by the diversity of the Bovidae, which is primarily a Plio-Pleistocene phenomenon. 